\title{
The relationship between body temperature, heart rate and respiratory rate in acute patients at admission to a medical care unit
}

\author{
Maria M Jensen ${ }^{1 *}$, Mikkel Brabrand ${ }^{2}$ \\ From 6th Danish Emergency Medicine Conference \\ Odense, Denmark. 20-21 November 2014
}

\section{Background}

An increase in body temperature (BT) is followed by an increase in heart rate (HR) and respiratory rate (RR). Only a few studies have explored the magnitude of this increase. These studies all included young healthy study subjects not taking any medicine that influenced the cardiovascular system. We wished to investigate this relationship in a study group more representative of the acute patients we meet in an emergency department.

\section{Methods}

Vital parameters from 4,493 acute patients obtained at admittance to the medical admission unit at Sydvestjysk Sygehus, Esbjerg, were retrospectively extracted from the hospital database. Linear and multiple variable regression analysis was used to calculate the change in $\mathrm{HR}\left(\Delta \mathrm{HR} /{ }^{\circ} \mathrm{C}\right)$ and $\mathrm{RR}\left(\Delta \mathrm{RR} /{ }^{\circ} \mathrm{C}\right)$ corresponding to variations in $\mathrm{BT}$ for the entire study group and after dividing the group in low $\left(<36.4^{\circ} \mathrm{C}\right)$, normal $\left(36.4-37.2^{\circ} \mathrm{C}\right)$ and high $\left(>37.2^{\circ} \mathrm{C}\right) \mathrm{BT}$.

\section{Results}

The study population consisted of 2,219 males and 2,274 females with a mean age of $62.2 \pm 19.2$ years. The $\Delta \mathrm{HR} /{ }^{\circ} \mathrm{C}$ and $\Delta \mathrm{RR} /{ }^{\circ} \mathrm{C}$ for the whole population was $7.2 \pm 0.4$ beats per minute $(\mathrm{bpm})$ and $1.4 \pm 0.1$ breaths per minute (brpm). When adjusting for age, oxygen saturation and mean blood pressure, the results were $6.4 \pm 0.4 \mathrm{bpm}$ and $1.2 \pm 0.1 \mathrm{brpm}$, respectively. In groups with low, normal and high $\mathrm{BT}$ the $\Delta \mathrm{HR} /{ }^{\circ} \mathrm{C}$ for the three groups were $2.7 \pm 1.9,6.9 \pm 1.9$ and $7.4 \pm 0.9 \mathrm{bpm}$, respectively. With

regard to $\Delta \mathrm{RR} /{ }^{\circ} \mathrm{C}$ the values were $-0.5 \pm 0.5,1.5 \pm 0.5$ and $2.3 \pm 0.3 \mathrm{brpm}$, respectively.

\section{Conclusions}

The previously most widely cited study on the association between BT and HR was performed in 1951 and reported a $\triangle \mathrm{HR} /{ }^{\circ} \mathrm{C}$ of $14.7 \mathrm{bpm}$. Later studies have shown a mean $\Delta \mathrm{HR} /{ }^{\circ} \mathrm{C}$ of $9.7 \mathrm{bpm}$. We have been unable to locate any references for the association between $\mathrm{BT}$ and RR. However, a $\Delta R R /{ }^{\circ} \mathrm{C}$ of $2.0-4.0 \mathrm{brpm}$ seems to be mostly agreed upon in the literature. We found a somewhat lower $\Delta \mathrm{HR} /{ }^{\circ} \mathrm{C}$ and $\Delta \mathrm{RR} /{ }^{\circ} \mathrm{C}$ than previously reported, in our population of subjects, adjusting for age, oxygen saturation and mean blood pressure. The highest $\Delta \mathrm{HR} /{ }^{\circ} \mathrm{C}$ and $\Delta \mathrm{RR} /{ }^{\circ} \mathrm{C}$ were seen in the groups with the highest $\mathrm{BT}$. We found no significant trends in the groups with low BT.

\section{Authors' details}

'Emergency Department, Skånes University Hospital, Lund, Sweden. 2Emergency Department, Sydvestjysk Sygehus, Esbjerg, Denmark.

Published: 16 July 2015

\footnotetext{
doi:10.1186/1757-7241-23-S1-A12

Cite this article as: Jensen and Brabrand: The relationship between body temperature, heart rate and respiratory rate in acute patients at admission to a medical care unit. Scandinavian Journal of Trauma, Resuscitation and Emergency Medicine 2015 23(Suppl 1):A12.
}

\footnotetext{
* Correspondence: mariamaj1@hotmail.com

${ }^{1}$ Emergency Department, Skånes University Hospital, Lund, Sweden

Full list of author information is available at the end of the article
} 